\title{
Compartment Syndrome of the Foot associated with an Open Lisfranc Injury: A case report
}

\author{
by Travis Motley, DPM, FACFAS ${ }^{1}$, Harold Cesar, DPM $^{2}-$
}

The Foot and Ankle Online Journal 4 (10): 3

A high index of suspicion is required to recognize compartment syndrome in both closed and open fractures. ${ }^{1}$ Compartment syndrome of the foot is well-described with cases secondary to closed trauma. We present an unusual case of an open Lisfranc fracture with compartment syndrome. Diagnostic modalities are discussed and early diagnosis appears to improve the success of treatment.

Key words: Adhesive capsulitis, frozen ankle, ankle pain, adhesions.

Accepted: September, $2011 \quad$ Published: October, 2011

This is an Open Access article distributed under the terms of the Creative Commons Attribution License. It permits unrestricted use, distribution, and reproduction in any medium, provided the original work is properly cited. (The Foot and Ankle Online Journal (www.faoj.org), 2011 All rights reserved.

$\mathrm{C}$ ompartment syndrome is considered a surgical emergency. When not treated in a timely manner, compartment syndrome can lead to disastrous complications including muscle necrosis, Volkmann's contracture, neurological deficit, crush syndrome, and even death. ${ }^{1}$ There are reported cases of associated compartment syndrome in open fractures of the lower leg, however not in the foot. ${ }^{2}$ As classically described, compartment syndrome results from increased interstitial pressure in a closed osseofascial compartment, which leads to micro vascular compromise. ${ }^{3}$ Typically, interstitial pressures in a closed osseofascial compartment are less than intravenous pressures.

Address correspondence to: Travis Motley, DPM, MS, FACFAS

John Peter Smith Hospital, 1500 South Main Street, Fort Worth, TX 76104.

Tmotley@jpshealth.org

1 Associate Professor, University of North Texas Health Science Center. John Peter Smith Hospital, Department of Orthopedics, Podiatry Division, 1500 South Main Street, Ft. Worth, TX 76104.

2 PGY-2, John Peter Smith Hospital, Department of Orthopedics, Podiatry Division, 1500 South Main Street, Ft. Worth, TX 76104.
This pressure gradient allows the venous system to remain patent. When the interstitial pressure surpasses that of the intravenous pressure the veins collapse and capillary blood flow ceases. This results in swelling and increase compartment pressures. ${ }^{4}$ Webber and Manoli identified nine compartments in the foot. Three compartments run the entire length of the foot, five compartments are contained within the forefoot, and a calcaneal compartment. ${ }^{5}$ The consensus in the treatment of compartment syndrome is to reduce pressure in order to restore perfusion. Immediate fasciotomy is recommended to prevent long-term complications. ${ }^{6,7}$ 


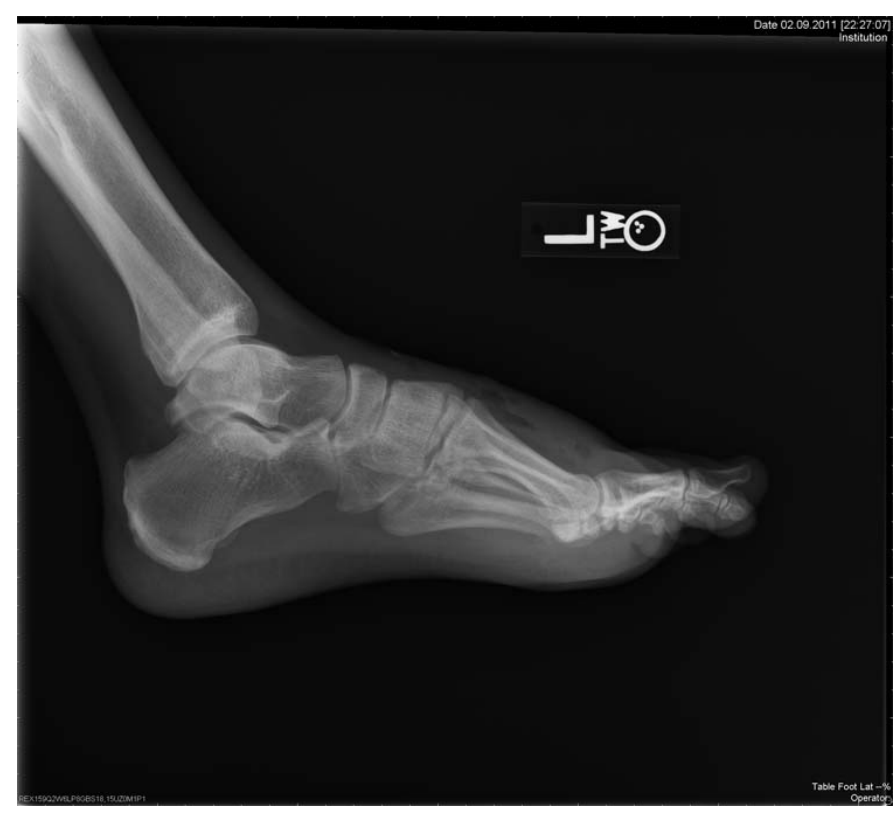

Figure 1 lateral view showing subcutaneous air dorsally.

\section{Case report}

A 48-year-old male was brought to the Emergency Department (ED) after a motor vehicle collision (MVC). After thorough evaluation by the trauma team, the patient was found to have suffered multiple rib fractures, a left knee laceration, and a left open Lisfranc fracture. The patient was admitted for a 23hour observation and Foot and Ankle Surgery (FAS) was consulted for the management of the open Lisfranc fracture. The FAS evaluated the patient two hours after arriving to the ED. The patient's past medical history was significant for diabetes mellitus, hypertension, and depression. He denied prior surgeries and known drug allergies. His current medications included metformin, lisinopril, and Zoloft $^{\mathrm{TM}}$ or sertraline). The patient related to occasional alcohol consumption and occasional chewing of tobacco.

During the evaluation process by FAS, the patient complained of severe pain in the left foot. The patient reported unchanged pain level even after multiple doses of analgesics in the ED.

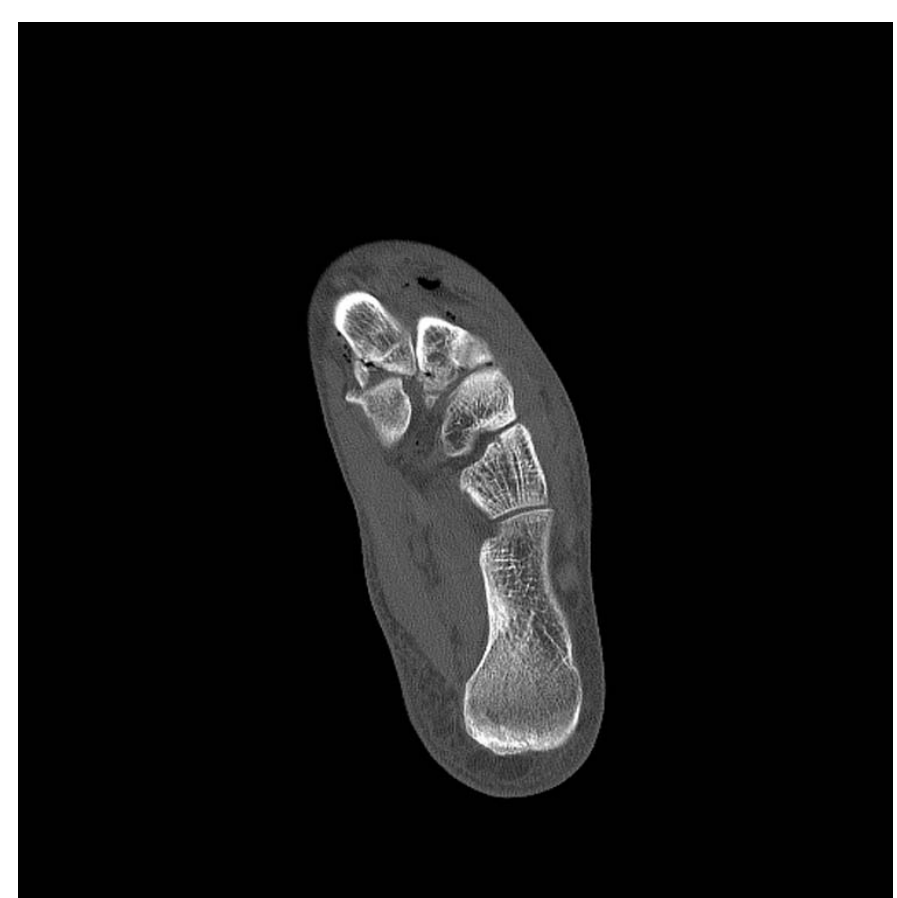

Figure 2 Axial view shows the Lisfranc injury with subcutaneous and intramuscular air bubbles.

He was administered $4 \mathrm{mg}$ of Dilaudid $^{\mathrm{TM}}$ or hydromorphone hydrochloride and $2 \mathrm{mg}$ of morphine over a two hour period before he was evaluated by FAS. Pain was elicited with palpation of the dorsal aspect of the left foot and with passive range of motion of the metatarsophalangeal joints. The dorsal aspect of the foot was tense upon palpation. Both dorsalis pedis and posterior tibial arteries were palpable. There was a $2.5 \mathrm{~cm}$ to $3 \mathrm{~cm}$ longitudinal laceration over the third inter-metatarsal space of the patient's left foot consistent with a grade II open injury. ${ }^{8}$ There was an associated +2 edema to the dorsal aspect of the left foot. The $3^{\text {td }}, 4^{\text {th }}$, and $5^{\text {th }}$ digits of the patient's left foot appeared dusky however capillary refill time was less than three seconds to all of the digits.

Radiographic examination revealed a first metatarsal base fracture with mild widening of the first tarsometatarsal joint. Computer Tomography (CT) revealed comminuted fractures of the proximal first and second metatarsals with intra-articular extension. The first and second metatarsal bases were displaced laterally. 


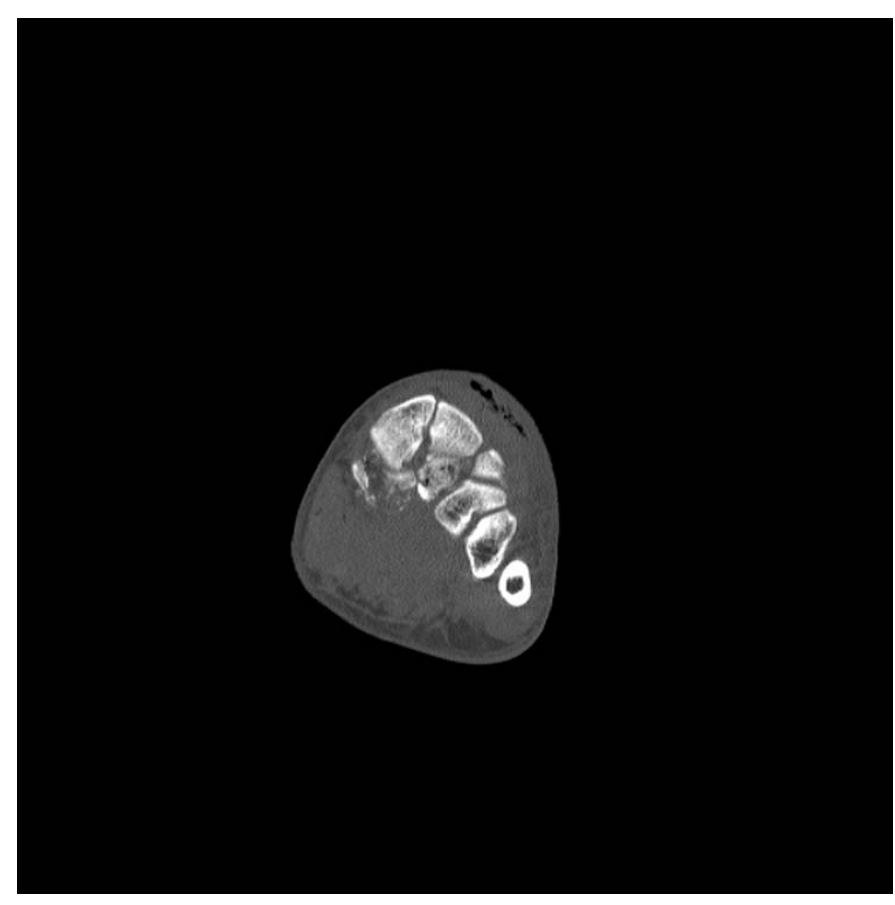

Figure 3 Frontal view also shows the Lisfranc injury with subcutaneous air.

There were intra-articular fractures of third and fourth metatarsal bases noted without displacement. There was diffuse soft tissue swelling with numerous scattered subcutaneous and intramuscular air bubbles. (Figs. 1, 2 and 3)

The patient was taken to the operating room for decompression fasciotomy of the left foot. The laceration on the dorsal aspect of the patient's foot was extended proximally and distally. Upon decompression of the interosseous compartment, there was approximately forty to fifty cubic centimeters of hematoma released from the wound. After evacuating this hematoma, the dorsal aspect of the left foot was soft upon palpation and there was hyperemic response to digits 3-5. The remaining compartments were soft and were not released. The wound was then subsequently irrigated with 6 liters of normal saline. A negative pressure therapy device was then applied to the patient's left foot (Wound Vac $\mathrm{KCI}^{\mathrm{TM}}$, San Antonio).

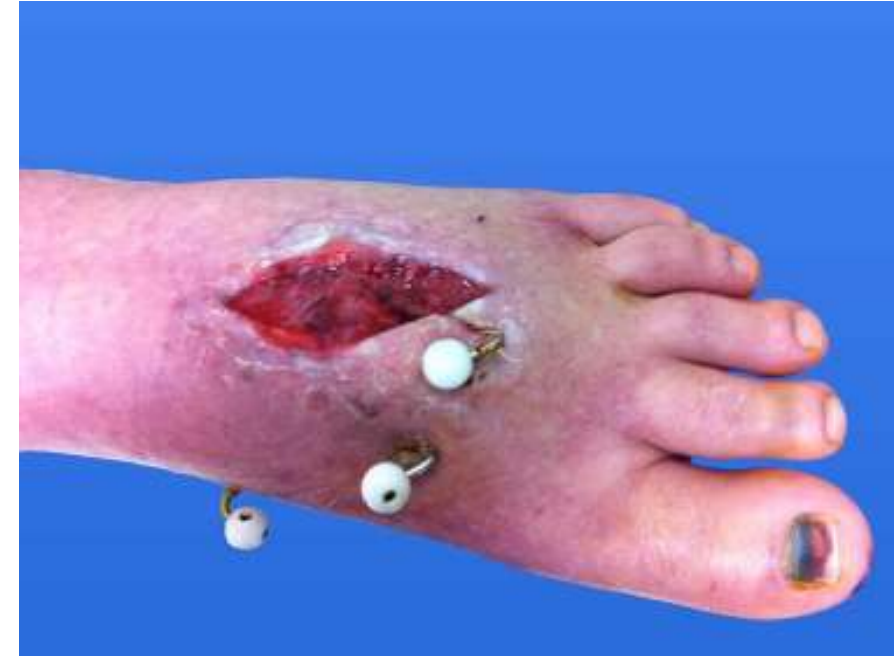

Figure 4 Left foot with dorsal wound and percutaneous Kirschner wires.

Four days later, the patient underwent a repeated irrigation and debridement with percutaneus fixation of the Lisfranc joint with Kirschner-wires. (Fig. 4) After a granular bed was achieved, the wound was subsequently covered with a split thickness skin graft at about 4 weeks.

\section{Discussion}

The diagnosis of compartment syndrome requires a high index of suspicion as this syndrome can occur after any injury regardless of mechanism. ${ }^{1}$ With open fractures however, it was postulated that compartment syndrome is not possible because there is an escape route for hematoma. Depending on the force, open fractures may decompress one or two compartments, but the remaining compartments may be at risk for developing compartment syndrome. Certain wounds do not decompress the underlying muscle by splitting the overlying fascia and thus are not able to accommodate swelling and therefore are not sufficient to allow decompression of the compartment. ${ }^{2} \mathrm{~A}$ hole in the compartment might not constitute adequate decompression because tissue does not flow like a liquid. ${ }^{4}$ 
There are multiple modalities available to objectively diagnose compartment syndrome such as intracompartment pressure monitoring (ICP), near infrared spectroscopy (NIRS), magnetic resonance imaging (MRI), scintigraphy, and laser Doppler flowmetry. There are several sources of error and learning curves associated with each of those modalities. ${ }^{1}$ It is recommended that compartment syndrome be confirmed by measuring the intracompartment pressure. ${ }^{4}$ In our patient we did not feel the need to measure the intra-compartment pressure, as clinical signs for compartment syndrome were present. Our patient had pain that remain unchanged since arriving to the ED despite the administration of multiple doses of analgesics. The dorsal aspect of the foot was tense, pain was elicited with passive range of motion, and there was pallor of the digits 3-5; All reliable clinical findings for compartment syndrome. ${ }^{6}$ In order to prevent disabling complications, early diagnosis derived from clinical findings is the key in the successful treatment of compartment syndrome. ${ }^{1}$

\section{References}

1. Elliott K, Johnstone AJ. Diagnosing acute compartment syndrome. J Bone Joint Surg [Br] 2003;85-B:625-32.

2. Blick SS, Brumback RJ, Poka A, Burgess AR, Ebraheim NA.

Compartment syndrome in open tibial fractures. J Bone Joint Surg [Am] 1996;68-A:1348-53.

3. Mubarak SJ, Owen CA, Hargens AR, Garetto LP, Akeson WH. Acute compartment syndromes: diagnosis and treatment with the aid of the wick catheter. J Bone Joint Surg [Am] 1978;60A:1091-5.

4. Matsen III, FA: Compartmental syndrome. A unified concept. Clin Orthop, 113:8-14, 1975

5. Manoli II, A; Weber, TG: Fasciotomy of the foot: an anatomical study with special reference to release of the calcaneal compartment. Foot Ankle, 10(5):267-75, 1990. 6. Myerson, M: Diagnosis and treatment of compartment syndrome of the foot. Orthopedics, 13(7):711-7, 1990.

7. Myerson, MS: Experimental decompression of the fascial compartments of the foot - the basis for fasciotomy in acute compartment syndromes. Foot Ankle, 8(6):308-14, 1988.

8. Gustilo, R. B., and Anderson, J. T.: Prevention of infection in the treatment of one thousand and twenty-five open fractures of long bones. J. Bone Joint Surg. 58A:453, 1976.

9. Rorabeck, CH, Macnab, I: Anterior Tibial Compartment syndrome Complicating Fractures of the Shaft of the Tibia. J

Bone and Joint Surg., 58-A: 549-550, June 1976 